\title{
Development and Validation of HPTLC Method for Quantification of Solanesol in Various Parts of Nicotiana tabacum Collected from Different Geographical Regions of India
}

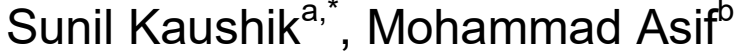 \\ Department of Pharmacy, GRD (PG) Institute of Management \& Technology, \\ Dehradun, India \\ asunilhamdard@gmail.com, baasif321@gmail.com
}

\begin{abstract}
Keywords: High-performance thin layer chromatography, Validation, Solanesol, Nicotiana
\end{abstract} tabacum

\begin{abstract}
Solanesol is the starting material for many high value biochemicals, including Coenzyme Q10 and vitamin-K analogues. The aim of the current study was to develop and validate a reliable and fast analytical procedure for the determination of solanesol in Nicotiana tabacum using high-performance thin layer chromatography (HPTLC) method. The method was developed on TLC aluminium plates precoated with silica gel 60F-254 using solvent system hexane: ethyl acetate $(5: 1, \mathrm{v} / \mathrm{v})$, which gives compact spot of solanesol ( $\mathrm{Rf}$ value $0.41 \pm 0.02)$. Densitometric analysis of solanesol was carried out in the absorbance mode at $210 \mathrm{~nm}$. The linear regression analysis data for the calibration plot showed good linear relationship with $r=0.9978$ with respect to peak area, in the concentration rang 100-5000 ng per spot of solanesol. The limit of detection and quantification were 13 and $30 \mathrm{ng}$ per spot, respectively. The proposed method was applied for quantitative estimation of solanesol in different parts of Nicotiana tabacum from different geographical regions in India, which showed that maximum amount of solanesol was found to be present in leaf sample collected from Karnataka i.e. $3.52 \mathrm{mg} / \mathrm{g}$. Statistical analysis proved that the method is repeatable, selective and accurate for the estimation of solanesol in Nicotiana tabacum.
\end{abstract}

\section{Introduction}

Solanesol is a trisesquiterpenoid alcohol (Fig. 1) which was first isolated from tobacco [1]. Tobacco belongs to family Solanaceae and the plant is considered to be a good source of a large number of bioactive substances and is the starting material for many high value bio-chemicals, including Co-enzyme Q10 and vitamin-K analogues. Solanesol is also a potentiating agent in many medicines. The research shows that after introducing "solanesol" radical into the structure of some medicines, the effect are increased distinctly. Solanesol can counteract the bacteria, diminish inflammation and hemostasis. It also has strong activity of counteracting the cancer. With solanesol as its primary material, Co-enzyme Q is useful in the treatment of heart diseases, cancers, ulcers, wound and so on. [2-10]. The content of solanesol in tobacco leaves is higher than that in any other organ [11]. A few methods for determination of solanesol in tobacco by HPLC [12-13], by GC [14], by HPLC-APCI-MS [15], and by LC-TMS [16], etc. have been reported. Till date, to best of our knowledge no HPTLC method for quantitative estimation of solanesol in different parts of Nicotiana tabacum from different geographical regions has been reported. Consequently a simple, precise and accurate HPTLC method for rapid quantification of solanesol was developed and the method was validated to achieve the satisfactory precision and recovery.<smiles>CC(C)=CCCC(C)=CCCO</smiles>

Fig. 1. Structure of solanesol $(3,7,11,15,19,23,27,31,35$-nonamethyl hexa triaconta$2,6,10,14,18,22,26,30,34-$ nonaen-1-ol) 


\section{Experimental}

\section{Drugs and chemicals}

The Nicotiana tabacum plants were collected from the local farms of Jhajjar (Haryana, India), Shimoga (Karnataka, India), Ayodhya (U.P., India) and Satara (Maharashtra, India). The leaf, stem and root parts were separated and dried at normal room temperature. The drugs were authenticated by Taxonomist of Department of Botany, Hamdard University. Reference standard Solanesol was obtained from Sigma Aldrich, China and all chemicals and reagents used were of analytical grade and were purchased from Merck, India.

\section{HPTLC instrumentation and conditions}

The samples were spotted in the form of bands of width $4 \mathrm{~mm}$ with a Camag microlitre syringe on percolated silica gel aluminium plate $60 \mathrm{~F}-254(20 \mathrm{~cm} \times 10 \mathrm{~cm}$ with $0.2 \mathrm{~mm}$ thickness, E. Merck, Germany) using a Camag Linomat V applicator(Switzerland). A constant application of $100 \mathrm{~nL} / \mathrm{s}$ was employed and space between two bands was $8.3 \mathrm{~mm}$. The slit dimension was kept at $4 \mathrm{~mm} \times 0.45 \mathrm{~mm}$, and $20 \mathrm{~mm} / \mathrm{s}$ scanning speed was employed. The mobile phase consisted of hexane: ethylacetate (5:1). Linear ascending development was carried out in twin trough glass chamber saturated with mobile phase. The optimized chamber saturation time for mobile phase was 20 min at room temperature. The length of chromatogram run was $80 \mathrm{~mm}$. Subsequent to the development TLC plates were dried in a current of air-dryer. Densitometric scanning was performed on Camag TLC scanner IV in the absorbance mode at $210 \mathrm{~nm}$. The source of radiation utilized was deuterium and tungsten lamp.

\section{Calibration curves of solanesol}

The stock solution of solanesol $(1000 \mu \mathrm{g} / \mathrm{ml})$ was prepared in hexane. Different volumes of stock solution, $0.1,0.2,0.4,0.5,1,2,4,5 \mu \mathrm{L}$ were spotted in duplicate on TLC plate to obtain concentration of 100, 200, 400, 500, 1000, 2000, 4000, $5000 \mathrm{ng}$ per spot of solanesol, respectively. The data of peak height/area versus drug concentration were treated by linear least-square regression.

\section{Validation}

The proposed analytical method was validated as per the latest ICH guidelines $[17,18]$ and the statistical analysis was done using Excel 2000 (MS Office).

\section{Accuracy}

The recovery studies of solanesol were carried out by standard addition method. The preanalyzed samples were spiked with extra 50,100 and $150 \%$ of the standard solanesol and the mixtures were reanalysed by the proposed method. The experiment was conducted in triplicate.

\section{Precision}

The intra and inter day variation and inter analyst precision of six replicates for the determination of as carried out at three different concentration levels of 500, 1000, $5000 \mathrm{ng}$ per spot. The $\%$ RSD of peak area was calculated.

\section{Robustness of the method}

By introducing small changes in the mobile phase composition, the effects on the result were examined. Mobile phases having different composition of hexane and ethyl acetate were tried at 1000 ng concentration per spot and \% RSD of peak area was calculated.

\section{Limit of detection and limit of quantification}

In order to estimate the limit of detection (LOD) and limit of quantification (LOQ), blank hexane was spotted six times. The signal to noise level was determined. LOD was considered as 3:1 and LOQ as 10:1 [19]. 


\section{Determination of solanesol in different samples of Nicotiana tabacum}

All dried powdered samples of Nicotiana tabacum (1gm each of leaf and stem sample and $2 \mathrm{gm}$ of root samples) were sonicated with petroleum ether $(25 \mathrm{ml})$ for thirty minutes. The filtered petroleum ether extract obtained were concentrated under reduced pressure to dryness which were re-dissolved separately, in $1 \mathrm{ml}$ of chromatographic grade petroleum ether. Further, $1 \mu \mathrm{L}$ each of leaf, $5 \mu \mathrm{L}$ each of stem and $10 \mu \mathrm{L}$ each of root samples were applied in duplicate on pre-coated silica gel $60 \mathrm{~F}_{254}$ aluminium sheets for quantification using proposed method.

\section{Result and Discussion}

\section{Selection of mobile phase}

Several easily available solvents in different combination and concentrations were tried to obtain good resolution, compact spot and better separation of spot. Lastly, the mobile phase consisting of hexane: ethyl acetate $(5: 1 \mathrm{v} / \mathrm{v})$ was selected which gives a sharp and well defined peak of solanesol at $R_{f}$ value of 0.41 . It was found that the solvent system has very good resolution for the separation of solanesol from other components of the extracts.

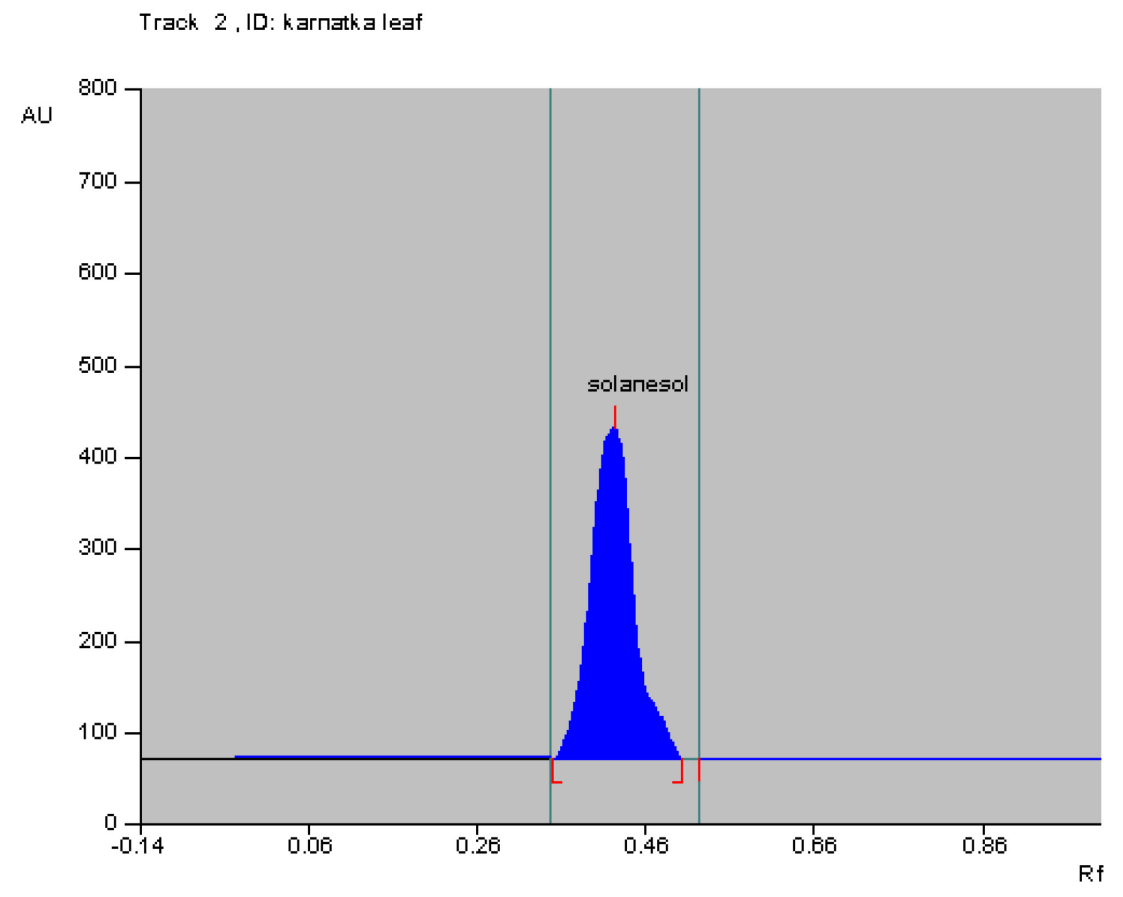

Fig. 2. A typical HPTLC chromatogram of solanesol $\left(\mathrm{R}_{\mathrm{f}}=0.41\right)$

\section{Calibration Curves}

\section{Linearity of the method}

The calibration curve $(n=3)$ was plotted by using peak area against concentration and was found linear in the range of $0.1 \mu \mathrm{g} / \mathrm{ml}$ to $5 \mu \mathrm{g} / \mathrm{ml}$ with a good correlation coefficient of 0.9978 . Calibration data, with their standard deviation of slope and intercept were given in Table1. Values obtained from the table indicated the method to be precise and reproducible. The linear regression data for the calibration plot were indicative of a good linear relationship between peak area and concentration over a wide range.

\section{Validation of Proposed Method}

The method was validated with respect to parameters including accuracy, precision, robustness, LOD and LOQ. 


\section{Recovery studies}

The proposed method when used for extraction and consequent estimation of solanesol after spiking with $0,50,100$ and $150 \%$ of the standard solanesol produced mean recovery of $100.475 \%$. The $\%$ RSD values after spiking with $0,50,100$ and $150 \%$ of additional drug were found in the range of 0.86-2.7. The result for the recovery has been incorporated in Table 2. The values of recovery study revealed the method is accurate for a wide range of concentration.

\section{Precision}

The proposed analytical method for repeatability and intermediate precisions were calculated and reported in terms of \%RSD in Table 3 and 4. Intermediate precisions included data of intra day, inter day and inter analyst precision. The low values of RSD indicated the reproducibility of method. The Intraday, Inter day and Inter analyst precision of solanesol were determined at three different concentration of 500, 1000, $5000 \mathrm{ng}$ per spot. The \% RSD was found in the range of 1.99$1.5 \%, 1.9-2.06 \%$ and $3.01-1.73 \%$ for repeatability and reproducibility.

\section{Robustness of the method}

The \%RSD of the peak areas was calculated for change in solvent system composition at concentrations $1000 \mathrm{ng}$ per spot in triplicate. The low values of \%RSD $(<4)$ obtained after introducing small deliberate changes in the developed HPTLC method indicated the robustness of method. The values are given in Table 5.

\section{LOD and LOQ}

The LOD and LOQ were determined by signal to noise ratio method and found to be $13 \mathrm{ng} /$ $\mathrm{ml}$ and $30 \mathrm{ng} / \mathrm{ml}$, respectively.

Table 1. Linear regression data for the calibration plot $(n=3)$

\begin{tabular}{ll}
\hline Linearity range (ng/ml) & $\mathbf{1 0 0 - 5 0 0 0}$ \\
\hline Regression equation & $1308.45+3.902 \mathrm{x}$ \\
Correlation coefficient & 0.9978 \\
Slope \pm S.D & $1341.0 \pm 29.4$ \\
Intercept \pm S.D & $3.809 \pm 0.12$ \\
\hline
\end{tabular}

Table 2. Recovery /Accuracy of the method $(n=3)$

\begin{tabular}{ccccc}
\hline $\begin{array}{c}\text { \%o of standard } \\
\text { spiked to the } \\
\text { sample }\end{array}$ & $\begin{array}{c}\text { Amount of } \\
\text { standard spiked } \\
(\boldsymbol{\mu g})\end{array}$ & $\begin{array}{c}\text { Amount of drug } \\
\text { recovered }(\boldsymbol{\mu g}) \pm \text { S.D }\end{array}$ & $\begin{array}{c}\text { \% of drug } \\
\text { recovered }\end{array}$ & $\begin{array}{c}\text { \% } \\
\text { RSD }\end{array}$ \\
\hline 0 & 3520 & $3512.9 \pm 36.6$ & 99.7 & 1.03 \\
50 & 5280 & $5375.0 \pm 60.3$ & 101.8 & 1.13 \\
100 & 7040 & $7307.5 \pm 205.0$ & 103.8 & 2.7 \\
150 & 8800 & $7728.0 \pm 66.4$ & 96.6 & 0.86 \\
\hline
\end{tabular}

Table 3. Repeatability of the method $(n=3)$

\begin{tabular}{lllllll}
\hline $\begin{array}{l}\text { Concentration } \\
(\mathbf{n g} / \mathbf{m l})\end{array}$ & $\begin{array}{l}\text { Mean area } \pm \\
\text { S.D }\end{array}$ & $\begin{array}{l}\text { Mean } \\
\text { height } \pm \\
\text { S.D }\end{array}$ & $\mathbf{R}_{\mathbf{f}} \pm$ S.D & $\begin{array}{l}\text { \% RSD } \\
\text { of area }\end{array}$ & $\begin{array}{l}\text { \% RSD } \\
\text { of } \\
\text { height }\end{array}$ & $\begin{array}{l}\text { \% RSD } \\
\text { of Rf }\end{array}$ \\
\hline 500 & $3405.7 \pm 65.1$ & $157.7 \pm 3.3$ & $0.41 \pm 0.01$ & 1.9 & 2.05 & 2.7 \\
1000 & $5826.3 \pm 200.3$ & $246 \pm 6.2$ & $0.43 \pm 0.01$ & 3.5 & 2.48 & 3.5 \\
5000 & $20574 \pm 525.9$ & $551.7 \pm 20.1$ & $0.46 \pm 0.01$ & 2.6 & 3.77 & 3.4 \\
\hline
\end{tabular}


Table 4. Intermediate precision of the method $(n=3)$

\begin{tabular}{lllllll}
\hline \multirow{2}{*}{$\begin{array}{l}\text { Concentration } \\
(\mathbf{n g} / \mathbf{m l})\end{array}$} & \multicolumn{2}{l}{ Interday precision } & \multicolumn{2}{l}{ Intraday precision } & \multicolumn{2}{l}{ Inter analyst precision } \\
\cline { 2 - 7 } & $\begin{array}{l}\text { Mean } \\
\text { area } \pm \text { S.D } \\
(\mathbf{n}=\mathbf{3})\end{array}$ & $\mathbf{\%}$ \%SD & $\begin{array}{l}\text { Mean } \\
\mathbf{a r e a} \pm \text { S.D } \\
(\mathbf{n = 3})\end{array}$ & $\mathbf{\%}$ \%SD & $\begin{array}{l}\text { Mean } \\
\text { area } \pm \text { S.D } \\
(\mathbf{n}=\mathbf{3})\end{array}$ & \%RSD \\
\hline 500 & $3266 \pm 67.09$ & 2.06 & $3312 \pm 50.5$ & 1.5 & $3308 \pm 56.22$ & 1.73 \\
1000 & $5785 \pm 145.6$ & 2.6 & $5646 \pm 96.0$ & 1.7 & $5714 \pm 137.3$ & 2.45 \\
5000 & $20692 \pm 400.4$ & 1.9 & $20646 \pm 407.3$ & 1.99 & $21402 \pm 659.5$ & 3.01 \\
\hline
\end{tabular}

Table 5. Robustness of the method (concentration 1000ng/ml)

\begin{tabular}{|c|c|c|c|c|c|}
\hline \multicolumn{2}{|c|}{$\begin{array}{l}\text { Solvent system } \\
\text { (Hexane : Ethyl Acetate) }\end{array}$} & \multirow{2}{*}{$\begin{array}{l}\text { Mean area } \\
\pm \text { S.D }(n=3)\end{array}$} & \multirow{2}{*}{$\begin{array}{l}\text { Mean } R_{f} \pm \text { S.D } \\
(n=3)\end{array}$} & \multirow{2}{*}{$\begin{array}{l}\% \text { RSD } \\
\text { of area }\end{array}$} & \multirow{2}{*}{$\begin{array}{l}\% \text { RSD } \\
\text { of } R_{f}\end{array}$} \\
\hline Original & Used & & & & \\
\hline \multirow{3}{*}{$5: 1$} & 4.9:1.1 & $5721 \pm 153.8$ & $0.42 \pm 0.015$ & 2.7 & 3.6 \\
\hline & $5: 1.1$ & $5737 \pm 78.3$ & $0.44 \pm 0.015$ & 1.4 & 3.5 \\
\hline & 5:0.9 & $5715 \pm 68.1$ & $0.44 \pm 0.017$ & 1.2 & 3.7 \\
\hline
\end{tabular}

\section{Determination of solanesol in different samples of Nicotiana tabacum}

The concentration of solanesol in different parts (leaf, stem and root) of Nicotiana tabacum from different geographical regions in India were determined by HPTLC and the result showed that the content of solanesol were significantly different from the different parts of Nicotiana tabacum. The maximum concentration of solanesol was observed in leaves, followed by stems and roots, respectively. The amount of solanesol was found to be 3.5204, 2.2010, 1.1590, 2.5020, 0.7339, 0.6944, 0.3468, 0.37190, 0.0823, 0.0078, $0.0817 \mathrm{mg} / \mathrm{g}$ sample collected from Karnataka (leaf), Maharashtra(leaf), U.P(leaf), Haryana(leaf), Karnataka(stem), Maharashtra(stem), U.P(stem), Haryana(stem), Karnataka(root), Maharashtra(root) and Haryana(root) respectively in drug. The maximum amount of solanesol was found to be present in leaf sample collected from Karnataka i.e. $3.52 \mathrm{mg} / \mathrm{g}$. The root sample collected from Karnataka and Haryana were having almost same amount of solanesol. Root sample collected from Maharashtra contain minimum amount of solanesol i.e. $0.0078 \mathrm{mg} / \mathrm{g}$. Root sample collected from U.P contain very less amount of solanesol which cannot be quantified. A very large variation in solanesol content of Nicotiana tabacum samples collected from different regions was found which may be attributed to several factors, such as local climate, growing conditions, harvest season, and so on. The low \% RSD values indicated the suitability of this method for routine analysis of solanesol in crude drugs.

\section{Conclusions}

An efficient procedure using HPTLC has been developed for rapid analysis and quantification of solanesol in different parts of $N$. tabacum from different geographical regions in India and successfully validated. The proposed analytical procedure provided an alternative simple, precise, fast, accurate and cost effective method for rapid determination of solanesol in N. tabacum, and was successfully applied on samples from different growing regions in India. The statistical analysis of data obtained proves that the method is reproducible and selective and can be used for routine analysis of solanesol in crude drugs. Finally, the study confirmed that the content of solanesol in leaves was higher than that in stems and roots of $N$. tabacum.

\section{Conflict of Interest}

The authors declare that there is no conflict of interest. 


\section{Acknowledgement}

Authors are thankful to Dr. Sayeed Ahmad, Department of Pharmacognosy and Phytochemistry, Jamia Hamdard University, New Delhi, India for providing the guidance and facilities to carry out this research work.

\section{References}

[1] R.L. Rowland, P.H. Latimer, J.A. Giles, Flue cured tobacco. Isolation of solanesol an unsaturated alcohol, Journal of the American Chemical Society. 78(18) (1956) 4680-4683.

[2] C. Zhao, Y. Zu, C. Li, Extraction of solanesol from tobacco leaves by bubble column, Chemical Engineering and Processing. 48 (2009) 203-208.

[3] H.Y. Zhou, C.Z. Liu, Microwave-assisted extraction of solanesol from tobacco leaves, J. Chromatogr. A. 1129 (2006) 135-139.

[4] Y.G. Zu et al., A rapid and sensitive LC-MS/MS method for determination of coenzyme Q10 in tobacco leaves, J. Sep. Sci. 29 (2006) 1607-1612.

[5] J.H. Wang et al., Design, synthesis and synergistic effects of novel derivatives of solanesol, Chemical Research in Chinese Universities. 23 (2007) 417-420.

[6] N. Schechter, T. Nishino, H. Rudney, The synthesis of 3-nonaprenyl-4-hydroxybenzoate in rat liver mitochondria: The effect of $\mathrm{Ca}^{2+}, \mathrm{Mg}^{2+}$, chelators, aghubinand bacitracin on the activity of p-hydroxybenzoate-polyprenyl transferase, Archives of Biochemistry and Biophysics. 158(1) (1973) 282-287.

[7] S. Srivastava et al., Novel hybrid natural products derived from solanesol as wound agent, Indian Journal of Chemistry. 48B (2009) 237-247.

[8] H. Suzuki, A. Tomida, T. Nishimura, Cytocidal activity of a synergistic isoprenoid, Nsolanesyl -N, N'bis (3,4 -dimethoxybenzyl) ethylenediamine, and its potentiation of anti tumor drugs against multidrug resistant and sensitive cells in vitro, Jpn. J. Cancer Res. 81 (1990) 298-303.

[9] S. Nyiredy, G.A. Gross, O. Sticher, Minor alkaloids from Nicotiana Tabacum, J. Nat. Prod. 49(6) (1986) 1156-1157.

[10] M. Bentinger et al., Polyisoprenoid epoxides stimulate the biosynthesis of coenzyme Q and inhibit cholesterol synthesis, J. Biol. Chem. 283 (2008) 14645-14653.

[11] C.J. Zhao, Y.G. Zu, C.Y. Li, Distribution of solanesol in Nicotiana tabacum, Journal of Forestry Research. 18 (2007) 69-72.

[12] M.S. Zhang, J.X. Huang, Determination of solanesol in the extracts of tobacco leaves by high performance liquid chromatography, $\mathrm{Se} \mathrm{Pu}=$ Chinese journal of chromatography. 19(5) (2001) 470-471.

[13] J. Zhao, C. Wang, X. Sun, Determination of solanesol in the extract of tabacco leaves by HPLC, $\mathrm{Se} \mathrm{Pu}=$ Chinese journal of chromatography. 15(6) (1997) 544-545.

[14] R. F. Severson et al., Gas chromatographic method for the determination of free and total solanesol in tabacco, J. Chromatography. 139 (1978) 269-282.

[15] J. Chen et al., Optimization of HPLC-APCI-MS conditions for the qualitative and quantitative determination of total solanesol in tobacco leaves, J. Sep. Sci. 31 (2008) 137-42.

[16] C. Zhao, C. Li, Y. Zu, Rapid and quantitative determination of solanesol in Nicotiana tabacum by LC-TMS, J. Pharm. Biomed. Anal. 44(1) (2007) 35-40. 
[17] ICH. Text on Validation of Analytical Procedures, Harmonized Tripartite Guideline prepared within the International Conference on Harmonization of Technical Requirements for the Registration of Pharmaceuticals for Human Use. ICH-Q2A, Geneva, 1994.

[18] ICH. Text on Validation of Analytical Procedures: Methodology, Harmonized Tripartite Guideline prepared within the International Conference on Harmonization of Technical Requirements for the Registration of Pharmaceuticals for Human Use. ICH-Q2B, Geneva, 1996.

[19] ICH. Draft guidelines on validation of analytical procedures: definition and technology, federal register, Vol 60. IFPMA, Switzerland, 1995. 